\title{
PENGEMBANGAN BAHAN AJAR ELEKTRONIK BERBASIS MOBILE-LEARNING PADA MATA KULIAH OPTIK DI FKIP UNIVERSITAS JEMBER
}

\author{
Rifati Dina Handayani \\ Pendidikan Fisika FKIP universitas Jember \\ Koresponden: Jl. Kalimantan 37 Kampus Bumi Tegal Boto FKIP Universitas Jember, Jawa Timur. \\ e-mail: rifati.fkip@unej.ac.id
}

\begin{abstract}
In this global and modern era, the interaction between a teacher and students still could be done after teaching and learning process in the classroom because of the development of information technology. This research was aimed to to design electronic teaching materials based Mobile-Learning (M-Learning). This teaching material was designed by using the 4D Model which was reducted to become 3D: Define, Design, and Develop. The target of doing this research was electronic teaching materials based Mobile-Learning (M-Learning) at "Optik" (Optics) subject. This teaching material was presented by using electronic medium such as phonecell or tablet because they were very easy to bring whenever and wherever. Based on the result of the research, optics based M-Learning had been successfully designed and useful for students in learning process.
\end{abstract}

Kata kunci: bahan ajar optik, mobile learning

\section{PENDAHULUAN}

$\mathrm{P}$ ada era yang serba maju dan modern, kecanggihan teknologi nyebabkan pembelajaran tidak hanya berjalan dalam suatu kondisi yang tradisional dimana guru dan siswa saling bertemu dan berkomunikasi di dalam kelas. Tetapi pembelajaran sudah mulai bersifat modern dengan memanfaatkan teknologi modern seperti handphone, android, tablet, dsb. Mobile-Learning atau M-learning merupakan salah satu implementasi dari proses pembelajaran secara modern, dimana mahasiswa dapat melakukan pembelajaran kapanpun dan dimanapun. M-Learning adalah pembelajaran yang unik karena pebelajar dapat mengakses materi pembelajaran, arahan dan aplikasi yang berkaitan de- ngan pembelajaran, kapanpun dan dimanapun melalui perangkat telekomunikasi seperti handphone, smartphone dan tablet. Hal ini akan meningkatkan perhatian pada materi pembelajaran, membuat pembelajaran menjadi persuasif dan dapat mendorong motivasi pembelajar kepada pembelajaran sepanjang hayat (lifelong learning). Selain itu, dibandingkan pembelajaran konvensional, M-Learning memungkinkan adanya lebih banyak kesempatan untuk kolaborasi dan berinteraksi secara informal diantara pebelajar.

Secara umum tujuan penelitian ini adalah untuk mengembangkan bahan ajar elektronik dengan memanfaatkan perangkat elektronik seperti handphone dan tablet pada mata kuliah optik di FKIP Universitas Jember. Tujuan umum ini dapat dijabarkan ke dalam tujuan- 
tujuan yang lebih khusus, yaitu mengembangkan bahan ajar elektronik berbasis mobile learning, Mendeskripsikan keterlaksanaan pembelajaran mahasiswa menggunakan Bahan ajar elektronik berbasis mobile learning pada mata kuliah optik, Mendeskripsikan respon mahasiswa pada optik menggunakan mobile learning.

\section{METODE PENELITIAN}

Subyek uji coba pada penelitian ini adalah mahasiswa yang menempuh mata kuliah Optik di FKIP Universitas
Jember. Jenis penelitian adalah penelitian pengembangan dengan menggunakan model 4-D Thiagarajan yang direduksi menjadi model 3-D. Model pengembangan perangkat seperti disarankan oleh Thiagarajan, Semmel dan Semmel (1974) yang diadopsi oleh Ibrahim (2008) yaitu model 4-D (Four D Models) yang direduksi menjadi 3-D. Pengembangan model ini terdiri dari empat tahap, yaitu tahap Pendefinisian (Define), Perancangan (Design), Pengembangan (Develop). Adapun skema penelitian adalah sebagai berikut:

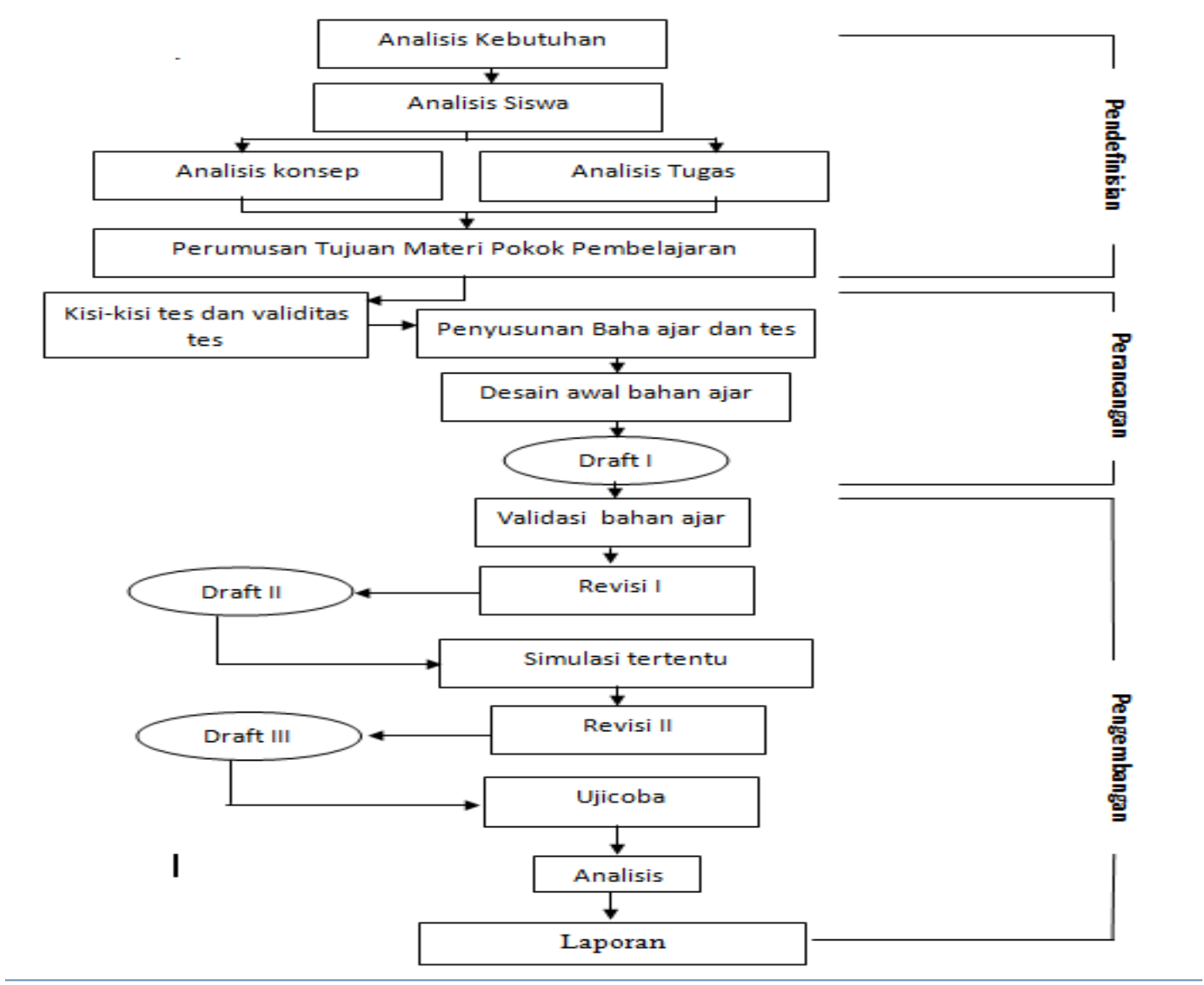

Gambar 1. Skema pelaksanaan Penelitian

(Sumber: Diadaptasi dari Ibrahim, 2008: 6)

\section{HASIL DAN PEMBAHASAN}

Penelitian ini dilaksanakan bulan nopember pada perkuliahan Optik. Bahan ajar yang dikembangkan me- rupakan bahan ajar dalam bentuk elektronik menggunakan mobile phone, sehingga mahasiswa dapat belajar kapanpun dan dimanapun. Akan tetapi untuk memaksimalkan penggunaan dari 
bahan ajar itu sendiri peneliti juga mengembangkan dalam bentuk hardcopy yang dipergunakan di dalam perkuliahan di kelas. Pada proses awal bahan ajar divalidasi oleh validator dengan hasil tampak seperti pada tabel 1 .

Tabel 1. Kriteria Validitas Bahan Ajar

\begin{tabular}{lcl}
\hline \multicolumn{1}{c}{ Aspek yang dinilai } & skor & \multicolumn{1}{c}{ kriteria } \\
\hline Keterbacaan Modul & 3 & Jelas dan dapat dipergunakan tanpa revisi \\
\hline Kejelasan tulisan & 3 & $\begin{array}{l}\text { Sangat jelas dan dapat dipergunakan } \\
\text { tanpa revisi }\end{array}$ \\
\hline Kedalaman materi & 2 & Cukup \\
\hline Bentuk Penyajian & 2 & Cukup \\
\hline Kelengkapan Bahan Ajar & 3 & $\begin{array}{l}\text { Sangat baik dan sesuai sehingga dapat } \\
\text { dipergunakan }\end{array}$ \\
\hline
\end{tabular}

Berdasarkan hasil dari validasi ahli disimpulkan bahwa bahan ajar optik dapat dipergunakan tanpa revisi. Untuk mengetahui respon mahasiswa disebar- kan angket terhadap mahasiswa penempuh mata kuliah optik pada kelas $\mathrm{x}$ sebanyak 20 mahasiswa menunjukkan hasil seperti tampak pada tabel 2 .

Tabel 2. Hasil Penilaian Mahasiswa Terhadap Bahan Ajar

\begin{tabular}{lccc}
\hline Kriteria dalam angket & \multicolumn{3}{c}{ Skor penilaian } \\
\cline { 2 - 4 } & 3 (tinggi) & 2 (sedang) & 1 (rendah) \\
\hline Kejelasan Materi & $89,10 \%$ & $11,90 \%$ & 0 \\
\hline Membantu mahasiswa dalam belajar & $93,10 \%$ & $6,90 \%$ & 0 \\
\hline Keterbacaan tulisan dalam modul & $53,33 \%$ & $40,00 \%$ & $6,67 \%$ \\
\hline Kebermanfaatan modul & $85,71 \%$ & $14,29 \%$ & 0 \\
\hline Modul perlu pengembangan & $72.00 \%$ & 24.00 & $04,00 \%$ \\
\hline
\end{tabular}

Penelitian ini merupakan penelitian pengembangan, dengan tujuan untuk mengembangkan modul pembelajaran optik pada mahasiswa semester $\mathrm{V}$ penempuh mata kuliah optik di kelas $X$. Bahan ajar yang dikembangkan adalah bahan ajar dalam bentuk mobile learning yang diharapkan dapat membantu mahasiswa dalam belajar sehingga pemahaman mereka terhadap konsep optik meningkat.

Dalam pelaksanaannya pengembangan mobile learning untuk bahan ajar optik menggunakan software Hot Lava Mobile (HLM) yang merupakan software bebas tanpa bayar, sehingga keresmian atau legalisasi dari program ini sangat terjamin. Program HLM di install di dalam komputer, kemudian bahan ajar optik yang sudah jadi dimasukkan dalam program, sehingga sesuai dengan mobile phone yang terbiasa dipergunakan oleh mahasiswa. Syarat dari penggunaan aplikasi ini adalah mobile phone memiliki program java.

Setelah mobile learning jadi peneliti terlebih dahulu melakukan validasi ahli untuk mengetahui aspek kejelasan materi, keterbacaan, keluasan materi dan bentuk penyajian. Dari hasil validasi ahli menunjukkan hasil bahwa modul optik dalam bentuk mobile dapat dipergunakan dalam penelitian tanpa 
revisi. Setelah melakukan validasi ahli dan bahan ajar dinyatakan valid maka peneliti membagikan bahan ajar ini kepada mahasiswa melalui aplikasi Bluetooth, sehingga mahasiswa dapat mempelajari bahan ajar kapanpun dan dimanapun. Selain menggunakan mobile phone sebagai media pembelajaran bahan ajar juga dicetak dalam bentuk hardcopy untuk perkuliahan yang dilakukan melalui tatap muka. Hal ini bertujuan untuk mempermudah mahasiswa dalam belajar di kelas.

Penelitian ini dilaksanakan selama 1 bulan atau sebanyak 2 kali tatap muka untuk mengetahui respon dari mahasiswa. Untuk mengetahui respon mahasiswa, dibagikan angket kepada mahasiswa penempuh mata kuliah optik melalui media online, yang meliputi 5 kriteria, yakni kejelasan materi dalam modul, keterbantuan mahasiswa dalam belajar karena adanya modul elektronik dalam bentuk M-Learning, keterbacaan tulisan Modul elektronik dalam Mlearning, kebermanfaatan modul elektronik, dan perlunya perbaikan atau pengembangan modul. Dari 5 aspek yang dipertanyakan kepada mahasiswa untuk mengetahui respon mereka, ternyata bahan ajar dalam bentuk mobile learning sangat membantu mahasiswa dalam belajar. Hal ini dapat dilihat pada tabel 4.2 dimana 18 reponden dari 20 menyatakan bahwa bahan ajar optik dalam bentuk mobile learning sangat membantu mahasiswa dalam belajar. Hal ini disebabkan karena kemudahan akses dan praktis. Sedangkan faktor keterbacaan tulisan sedikit mendapatkan respon yang bagus. Hal ini disebabkan karena jenis mobile phone yang dimiliki mahasiswa adalah tidak sama atau berbeda-beda sehingga resolusi gambar atau tulisan tidak begitu jelas. Hal yang menarik dari respon mahasiswa adalah perlunya pengembangan bahan ajar lebih lanjut yang ditunjukkan dengan $72.00 \%$. Hal ini benar-benar sangat disadari oleh peneliti karena bahan ajar yang digunakan masih sangat sederhana dan terbatas, sehingga perlu pengembangan lebih lanjut mengenai, aplikasi dan contohcontoh kasus, serta soal-soal agar mahasiswa lebih jelas dan lebih terbantu.

Beberapa kendala yang dihadapi dalam penelitian ini adalah tidak semua mobile phone memiliki software java sehingga program tidak bisa terbaca atau terkirim, selain itu karena menggunakan mobile aktivitas dari pembelajaran itu sangat sulit untuk diamati, sehingga peneliti mensiasati dengan memberikan modul dalam bentuk hardcopy atau cetak.

\section{PENUTUP}

Adapun simpulan yang diperoleh dari penelitian ini adalah

1. Bahan ajar optik dalam bentuk mobile learning sudah dapat dikembangkan dan dapat digunakan untuk proses pembelajaran

2. Bahan ajar optik yang dikembangkan dalam bentuk mobile learning bermanfaat bagi mahasiswa dan membantu dalam proses belajar.

Adapun saran dari hasil penelitian ini adalah

1. Perlu penambahan latihan soal dan contoh aplikasi dari masing-masing pokok bahasan yang terdapat dalam bahan optik sehingga mahasiswa lebih paham dan mengetahui aplikasinya dalam kehidupan seharihari

2. Perlu pengembangan mobile learning dengan menggunakan perangkat lain seperti tablet dan android. 


\section{DAFTAR RUJUKAN}

Arikunto, S. 2006. Prosedur Penelitian. Jakarta: Rineka Cipta.

Depdiknas. 2008b. Materi Sosialisasi dan Pelatihan Kurikulum Tingkat Satuan Pendidikan (KTSP) SMP: PERMEN 22 Th 2006 - Standar Isi (Standar Kompetensi dan Kompetensi Dasar). Jakarta: Depdiknas.

Ibrahim, M. 2008. Pengembangan Perangkat Pembelajaran. Jakarta: Dirjen Dikdasmen Depdiknas.
Trianto. 2010. Mendesain Model Pembelajaran Inovatif-Progresif. Jakarta: Kencana.

Waluyanto, H, D. 2005. Komik Sebagai Media Komunikasi Visual Pembelajaran. Jurnal Pendidikan, 7 (1): 45-55. 